\title{
Synthesis and characterization of new chiral ketopinic acid-derived catalysts immobilized on polystyrene-bound imidazole
}

\author{
Yusuf HASSAN, ${ }^{1 *}$ Rosa KLEIN, ${ }^{2}$ Perry T. KAYE ${ }^{2}$ \\ ${ }^{1}$ Department of Chemistry, Umaru Musa Yar'adua University, Katsina, Nigeria \\ ${ }^{2}$ Department of Chemistry, Rhodes University, Grahamstown, South Africa
}

\begin{abstract}
Four new chiral ketopinic acid-derived catalysts were anchored on a polystyrene-bound imidazole via non-covalent bond. The resulting heterogeneous catalysts were successfully characterized using IR, SEM, and TGA analyses.
\end{abstract}

Keywords: polymer, chiral catalysts, non-covalent bond.

\section{Introduction}

The ability of new chiral catalysts 1-4 (Scheme 1) derived from ketopinic acid to effect different asymmetric transformations, viz. aldol, BaylisHillman, aza-Michael, and reduction reactions was demonstrated [1]. These are widely employed methodologies in the syntheses of natural products and pharmaceutically important compounds [2-12]. However, the fact that these catalysts were homogenous provides the opportunity to explore methods of anchoring them onto a solid support to render them heterogeneous [13]. Heterogeneous catalysis has the potential advantages of easy separation, efficient recycling, and the minimization of metal trace in the product. There are also improved handling and process control issues that could, in principle, result in an overall reduction of costs and waste $[14,15]$.

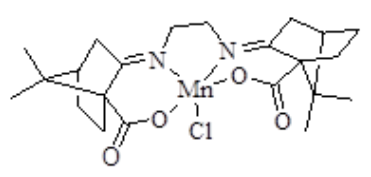

1

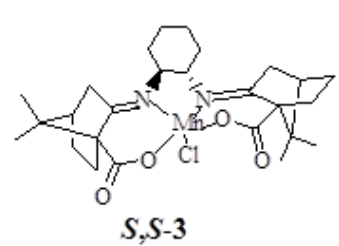

$S, S-3$

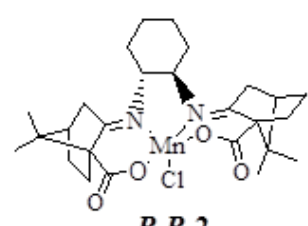

$R, R-2$

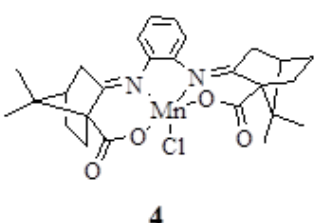

4
Scheme 1. Manganese chiral ketopinic acid-derived catalysts.

\footnotetext{
*Corresponding author: yusuf.hassan@umyu.edu.ng
}

\section{Experimental}

Reagent-grade acetonitrile, ether, ethylacetate, and methanol were used as received from commercial source. All other reagents were purchased from Aldrich and used as received. IR spectral measurements were carried out on a Perkin Elmer spectrum 400 FT-IR spectrometer (ATR). Thermogravimetric analyses of the catalysts were performed on Perkin Elmer 2000 TGA 7. Scanning electron micrographs of the catalysts were taken on a TESCAN VEGAN III XMU Q150 TE.

Synthesis of chiral ketopinic acid-derived catalysts 1-4. Catalysts 1-4 were prepared according to the standard procedure $[16,17]$.

Synthesis of polymer-supported catalysts 5-8. Polymer-bound imidazole: To a slurry of the Merrifield resin (1 g, $1 \mathrm{mmol})$ in acetonitrile $(6.5 \mathrm{~mL})$ were added imidazole $(0.68 \mathrm{~g}, 10 \mathrm{mmol})$ and $\mathrm{NaI}$ $(0.01 \mathrm{~g}, 0.07 \mathrm{mmol})$ and the mixture was refluxed with stirring for $48 \mathrm{~h}$. The resin was filtered off and washed successively with acetonitrile $(5 \times 5 \mathrm{~mL}), 10 \%$ aq. $\mathrm{K}_{2} \mathrm{CO}_{3} / \mathrm{MeOH}(1: 1), \mathrm{H}_{2} \mathrm{O} / \mathrm{MeOH}(1: 1), \mathrm{MeOH}$ and EtOAc $(5 \times 10 \mathrm{~mL}$ each). The solid was dried under vacuum overnight to yield polymer-bound imidazole $(1.00 \mathrm{~g}, 99 \%)$. IR (neat, $\left.\mathrm{cm}^{-1}\right)$ : 3025, 2919, 1492, 1451, 1265. General procedure for the immobilization of the catalysts: To a solution of 50 $\mathrm{mg}$ each of catalysts 1-4 in acetonitrile $(5 \mathrm{~mL})$ was added polymer-bound imidazole (375 mg). The mixture was vigorously stirred at $80^{\circ} \mathrm{C}$ for $24 \mathrm{~h}$. After cooling, the brown resin was collected by filtration, washed thoroughly with acetonitrile, methanol, and ether successively. It was then dried in vacuum at room temperature for several hours to afford complexes; 5 (93\%), R,R-6 (89\%), S,S-7 (83\%), and $8(90 \%)$ yield. SEM was used for characterization based on morphological changes. 


\section{Results and Discussion}

The aim was to incorporate catalysts 1-4 onto the Merrifield resin [18] by adopting the non-covalent immobilization approach [19]. A nitrogenous base (imidazole) would be tethered to the Merrifield resin and subsequently coordinated to the manganese atom of the chiral complex. The polymer-supported imidazole was expected to offer both the heterogeneous scaffold and provide an axial ligand in the corresponding catalytic complexes $\mathbf{5 - 8}$ as illustrated in Scheme 2 [20].

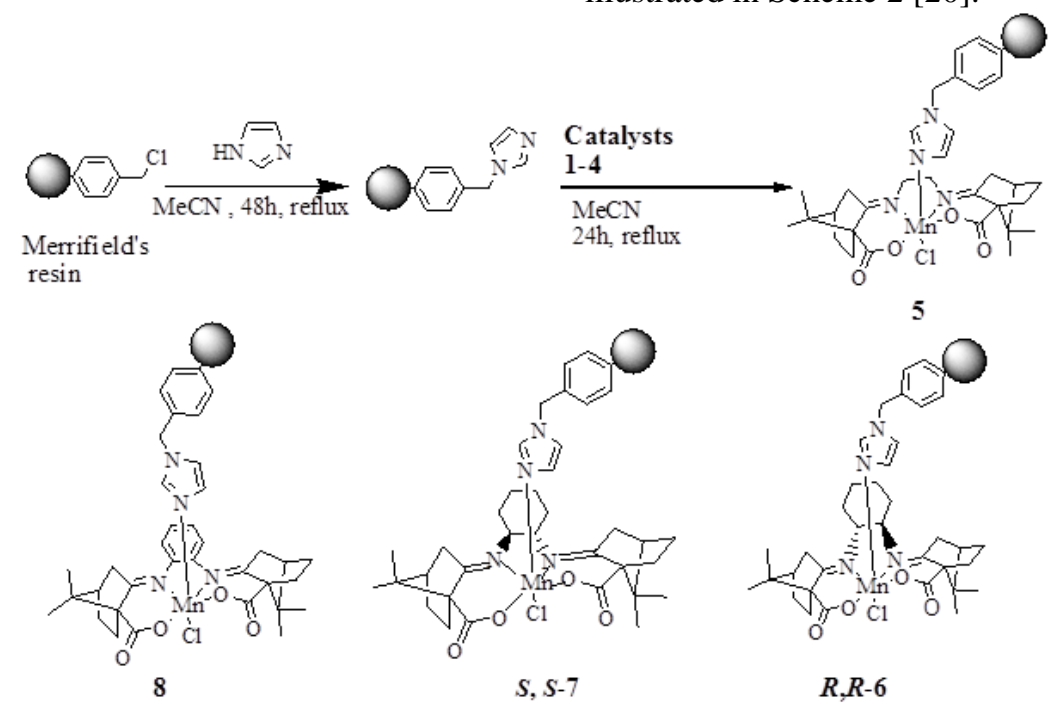

Scheme 2. Immobilization of the chiral catalysts 1-4 onto a polystyrene-bound imidazole.

The first step of the synthesis of the polystyrenesupported complexes 5-8 was the treatment of the Merrifield resin with an appropriate quantity of imidazole, in refluxing acetonitrile for $48 \mathrm{~h}$ [11]. After cooling, the resin was filtered off and washed with acetonitrile, mixture of aq. $\mathrm{K}_{2} \mathrm{CO}_{3} / \mathrm{MeOH}$ and $\mathrm{H}_{2} \mathrm{O} / \mathrm{MeOH}$ followed by $\mathrm{MeOH}$ and then EtOAc. The solid was dried under vacuum overnight and afforded the product in $99 \%$ yield. Elemental analysis of the isolated polystyrene-supported imidazole (PSI) revealed that the nitrogen content was $2.01 \%$ which was equivalent to $51 \%$ of the chlorine substituted. Confirmation of the presence of the imidazoylmethylene bond was explored using IR spectroscopy (Figure 1).

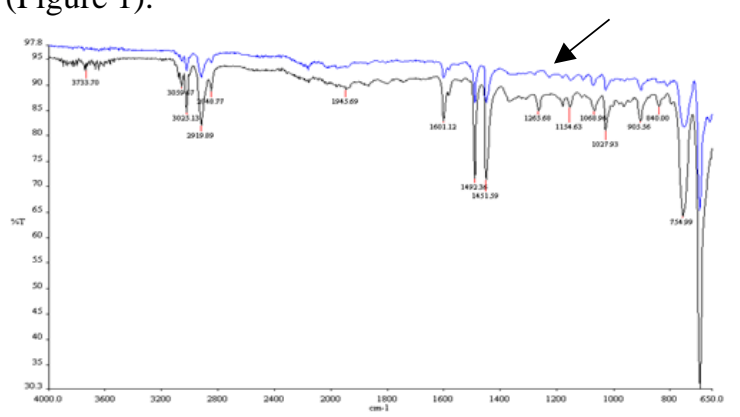

Figure 1. Overlaid IR spectra of Merrifield's resin and the PSI.

Due to the similarity between the Merrifield resin and the PSI in the mid-IR range, the two spectra were overlaid to carefully ascertain the band differences in this region. The lower spectrum is for the Merrifield resin and exhibits a weak band due to the $\mathrm{C}-\mathrm{Cl}$ bond at $1265.68 \mathrm{~cm}^{-1}$. Upon nucleophilic substitution of chloride by the imidazole nitrogen, the weak band has largely disappeared (top spectrum).

The supported chiral complex was then prepared by stirring a suspension of the PSI, in solutions of the metal complexes 1-4 in $\mathrm{CH}_{3} \mathrm{CN}$ as solvent [11] as shown on Scheme 2. After stirring at an elevated temperature $\left(80^{\circ} \mathrm{C}\right)$ for $24 \mathrm{~h}$, the mixture was cooled and, in each case, the resins were filtered off, washed sequentially with acetonitrile, methanol, and ether. Organic solvent washings were checked by IR until no unreacted complex was detected, and thus confirming the stability of the coordinative bond, to the PSI. Surface characterization of the supported catalysts was performed using Scanning Electron Microscopy (SEM). The images show some morphological changes on the surface of the polymer resin beads. SEM images of the Merrifield resin and immobilized catalyst $\mathbf{5}$ are shown in Figures 2 and 3 respectively.

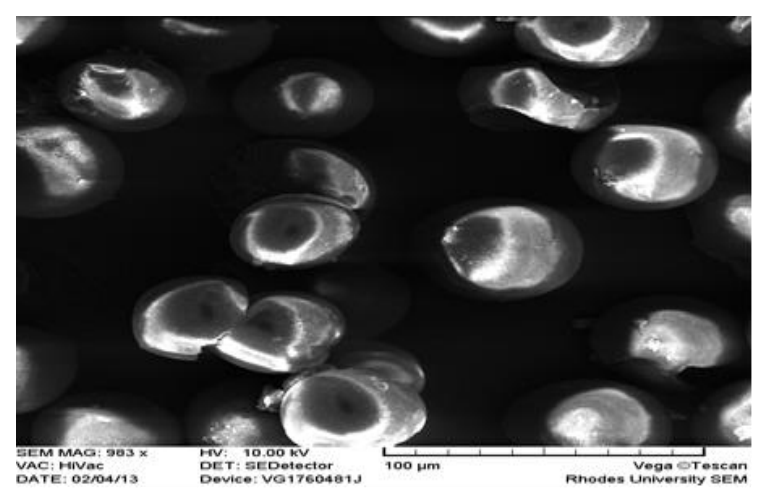

Figure 2. SEM image of Merrifield's resin. 


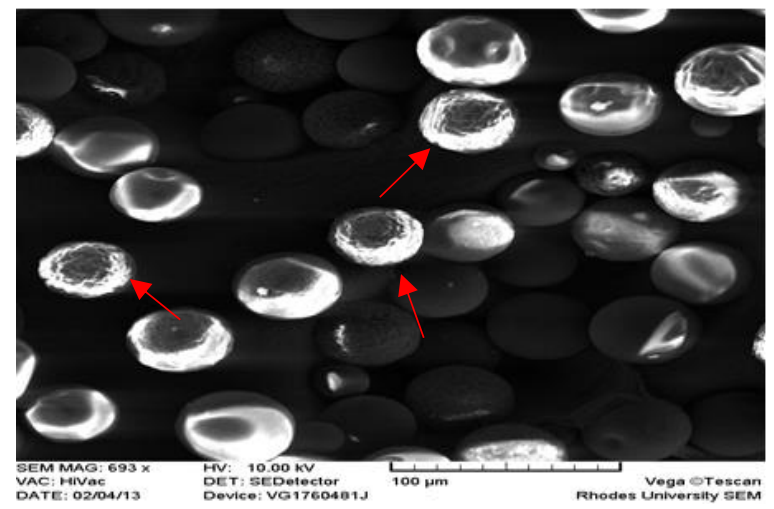

Figure 3. SEM image of the PSI-catalyst 5 with arrows indicating surface changes in the beads.

Finally, thermogravimetric analysis (TGA) was conducted to ascertain the stability of the supported catalysts [19]. The Merrifield resin shows single step degradation at approximately $280{ }^{\circ} \mathrm{C}$ (Figure 4). The supported catalysts on the other hand degrade at lower temperatures of approximately $200{ }^{\circ} \mathrm{C}$ as illustrated by the representative TGA curve of catalyst 5 (Figure 5). This corresponds to either the dissociation of the coordinative bound manganese complex or a partial scission of the polymeric chain. However, it seems that the supported catalysts are thermally stable up to $200{ }^{\circ} \mathrm{C}$.

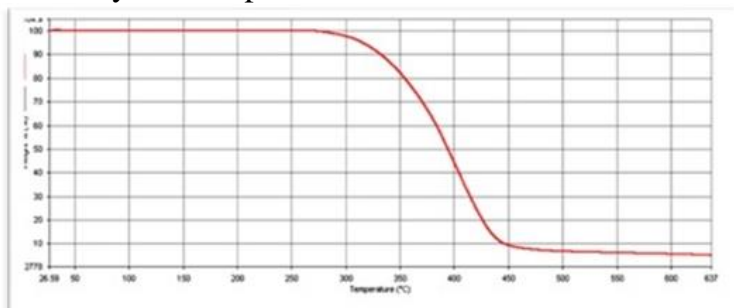

Figure 4. TGA curve of Merrifield's resin.

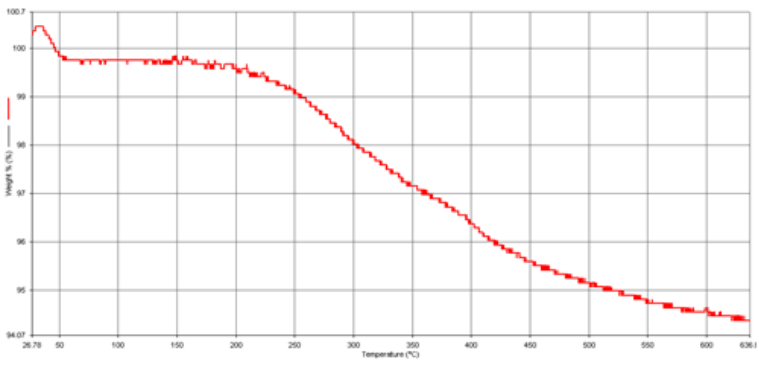

Figure 5. TGA curve of PSI-catalyst 5.

\section{Conclusions}

Chiral ketopinic acid-derived catalysts were successfully immobilized onto a polymer support via non-covalent interaction with polymer-bound imidazole. This offers a remarkable advantage because the imidazole also plays the role of an axial ligand in the structure of the catalysts. It is hoped that these heterogeneous catalysts would address some of the limitations that are generally associated with the homogenous catalysts. The application of these immobilized catalysts in the asymmetric reactions is currently in progress.

\section{Acknowledgements}

The financial support of the National Research Foundation and the Tertiary Education Trust Fund, Nigeria for granting fellowship to Yusuf Hassan is gratefully acknowledged.

\section{Conflict of interests}

The authors declare that there is no conflict of interests.

\section{References}

[1]. Y. Hassan, Synthesis of chiral ketopinic acidderived catalysts and their evaluation in asymmetric transformations, $\mathrm{PhD}$ Thesis, Rhodes University, pp. 1-173 (2015).

[2]. P.G. Hultin, L.M. Geary, The state of the art in asymmetric induction: the aldol reaction as a case study, Tetrahedron: Asymmetr. 20 (2009) 131-173. DOI: 10.1016/j.tetasy.2008.12.030

[3]. A. Córdova, W. Zou, I. Ibrahem, E. Reyes, M. Engqvist, W.W. Liao, Acyclic amino acidcatalyzed direct asymmetric aldol reactions: alanine, the simplest stereoselective organocatalyst, Chem. Commun. 28 (2005) 3586-3588. DOI: 10.1039/B507968N

[4]. C. Li, X.W. Feng, N. Wang, Y.J. Zhou, X.Q. $\mathrm{Yu}$, Biocatalytic promiscuity: the first lipasecatalysed asymmetric aldol reaction, Green Chem. $10 \quad$ (2008) 616-618. DOI: 10.1039/B803406K

[5]. Y.L. Liu, B.L. Wang, J.J. Cao, L. Chen, Y.X. Zhang, C. Wang, J. Zhou, Organocatalytic asymmetric synthesis of substituted 3-hydroxy2-oxindoles via Morita-Baylis-Hillman reaction, J. Am. Chem. Soc. 132 (2010) 1517615178. DOI: $10.1021 /$ ja107858z

[6]. D.V. Basavaiah, B.S. Reddy, S.S. Badsara, Recent contributions from the Baylis-Hillman reaction to organic chemistry, Chem. Rev. 110 (2010) 5447-5674. DOI: 10.1021/cr900291g

[7]. Q. Gu, S.L. You, Desymmetrization of cyclohexadienones viacinchonine derived thiourea-catalyzed enantioselective azaMichael reaction and total synthesis of (-)mesembrine, Chem. Sci. 2 (2011) 1519-1522. DOI: $10.1039 / \mathrm{C} 1 \mathrm{SC} 00083 \mathrm{G}$

[8]. Z. Amara, J. Caron, D. Joseph, Recent contributions from the asymmetric azaMichael reaction to alkaloids total synthesis, Nat. Prod. Rep. 30 (2013) 1211-1225. DOI: 10.1039/C3NP20121J

[9]. A. Jakoblinnert, R. Mladenov, A. Paul, F. Sibilla, U. Schwaneberg, M.B. AnsorgeSchumacher, P.D. de María, Asymmetric reduction of ketones with recombinant $E$. coli 
whole cells in neat substrates, Chem. Commun. 47 (2011) 12230-12232. DOI: 10.1039/C1CC14097C

[10]. Z.H. Yang, L. Luo, X. Chang, W. Zhou, G.H. Chen, Y. Zhao, Y.J. Wang, Production of chiral alcohols from prochiral ketones by microalgal photo-biocatalytic asymmetric reduction reaction, J. Ind. Microbiol. Biotechnol. 39 (2012) 835-841. DOI: 10.1007/s10295-0121088-y

[11]. M. Hayashi, T. Tamura, M. Shoji, The chiral diamine mediated asymmetric Baylis-Hillman reaction, Adv. Synth. Catal. 346 (2004) 11061110. DOI: $10.1002 /$ adsc. 200404069

[12]. (a) G. Cardillo, C. Tomasini, Asymmetric synthesis of $\beta$-amino acids and $\alpha$-substituted $\beta$ amino acids, Chem. Soc. Rev. 25 (1996) 117128. DOI: $10.1039 / \mathrm{CS} 9962500117$

(b) F.F. Blicke, Mannich reaction, Org. React. 1 (1942) 303.

DOI:10.1002/0471264180.or001.10

(c) M. Tramontini, L. Angiolini, Further advances in the chemistry of Mannich bases, Tetrahedron 46 (1990) 1791-1837. DOI: 10.1016/S0040-4020(01)89752-0

(d) M. Arend, B. Westermann, N. Risch, Modern variants of the Mannich reaction, Angew. Chem. Int. Ed. 37 (1998) 1044-1070. DOI: 10.1002/(SICI)1521-3773(19980504)37

(e) S. Kobayashi, H. Ishitani, Catalytic enantioselective addition to imines, Chem. Rev. 99 (1999) 1069-1094. DOI: 10.1021/cr980414z

[13]. T.S. Reger, K.D. Janda, Polymer-supported (salen)Mn catalysts for asymmetric epoxidation: A comparison between soluble and insoluble matrices, J. Am. Chem Soc. 122 (2000) 6929-6934. DOI: 10.1021/ja000692r

[14]. H. Han, K.D. Janda, Soluble polymer-bound ligand-accelerated catalysis: asymmetric dihydroxylation, J. Am. Chem Soc. 118 (1996) 7632-7633. DOI: $10.1021 /$ ja9608095
[15]. B.B. De, B.B. Lohray, S. Sivaram, P.K. Dhal, Polymeric catalysts for chemo- and enantioselective epoxidation of olefins: New crosslinked chiral transition metal complexing polymers, J. Polym. Sci. A-Polym. Chem. 35 (1997) 1809-1818. DOI: 10.1002/(SICI)10990518(19970715)35

[16]. K.S. Yang, W.D. Lee, J.F. Pan, K. Chen, Chiral Lewis acid - catalyzed asymmetric Baylis Hillman reactions, J. Org. Chem. 68 (2003) 915919. DOI: $10.1021 /$ jo026318m

[17]. R.I. Kureshy, N. Khan, S. Abdi, P. Iyer, A. Bhatt, Enantioselective catalytic epoxidation of nonfunctionalized prochiral olefins by dissymmetric chiral Schiff base complexes of $\mathrm{Mn}(\mathrm{III})$ and $\mathrm{Ru}(\mathrm{III})$ metal ions II, J. Mol. Cat. A-Chem. 120 (1997) 101-108. DOI: 10.1016/S1381-1169(96)00432-3

[18]. R.B. Merrifield, Solid phase peptide synthesis. I. The synthesis of a tetrapeptide, J. Am. Chem. Soc. 85 (1963) 2149-2154.

DOI: $10.1021 / \mathrm{ja} 00897 \mathrm{a} 025$

[19]. V. Mirkhani, M. Moghadam, S. Tangestaninejad, B. Bahramian, Polystyrenebound imidazole as a heterogeneous axial ligand for $\mathrm{Mn}$ (salophen) $\mathrm{Cl}$ and its use as biomimetic alkene epoxidation and alkane hydroxylation catalyst with sodium periodate, Appl. Catal. AGen. 311 (2006) 43-50. DOI: 10.1016/j.apcata.2006.05.043

[20]. M.L. Linares, N. Sanchez, R. Alajaran, J.J. Vaquero, J.A. Builla, Solid-support-bound 1aminoimidazolium chlorochromate: A selective, efficient and recyclable oxidant, Synthesis 3 (2001) 382-388. DOI: 10.1055/s2001-11431

Received: 12.02 .2017

Received in revised form: 17.02.2017

Accepted: 24.02.2017 